\title{
KRITIK SEYYED HOSSEIN NASR TERHADAP KLAIM KEBENARAN MODERNISME
}

\author{
Syairil Fadli*
}

\section{PENDAHULUAN}

Filsafat bermula dari kekaguman terhadap yang sederhana, pada gilirannya mampu melahirkan ilmu pengetahuan dalam berbagai bidang. Kekaguman itu ditandai dengan keinginan manusia menjawab rahasia alam, manusia, dan Tuhan. Manusia ingin memahami dan mengetahui apa yang dapat dilakukan terhadap apa yang mereka ketahui. Pertanyaan mendalam menjadi kebutuhan dan menghantui seperti: "Kenapa aku berada di jagad ini?"; "Apakah yang dimaksud dengan pengetahuan?"; "Apakah radikal itu?"; Hal senada diungkapkan oleh Seyyed Hossein Nasr, kapan dan di mana pun berada, manusia tidak dapat menghindari pertanyaan mendasar dengan serius, "Siapakah manusia?" "Dari mana manusia berasal?" "Apa yang manusia kerjakan?" dan "Akan ke mana manusia pergi?"2Leenhouwers ${ }^{3}$ berpendapat, dari sekian banyak pertanyaan, kalau diperas menjadi satu pertanyaan menentukan, yakni, "Apakah kebenaran itu?"

Menurut Descartes, persoalan dasar filsafat pengetahuan bukan bagaimana manusia dapat mengtahui, tetapi mengapa manusia dapat membuat kekeliruan. Kekeliruan muncul karena manusia mengira mengetahui yang tidak diketahui dan tidak mengetahui apa yang diketahui. Itu semua terjadi akibat tidak konsentrasi, kecurigaan, keangkuhan, dan emosi. ${ }^{4}$ Carruthers memberikan contoh, orang tidak akan tahu bahwa rumput itu hijau, kecuali orang itu percaya bahwa rumput itu (memang) betul-betul hijau sendiri. ${ }^{5}$

Kebenaran dalam konteks masa kini masuk dalam pemahaman kontemporer. Pada tataran hermeneutik, rasionalitas berfokus pada kemasukakalan (reasonable) yang menjadi titik temu keyakinan bahwa rasionalitas berhubungan erat dengan bahasa, kultur, praktek dan keyakinan bahwa argumentasi dan dialog hermeneutik itu menuntut rasionalitas komunikatif universal. Pemahaman kebenaran berada di antara medan konvensi dan gejala baru yang inkonvensional. $^{6}$

Manusia terpuruk dari dirinya dalam upaya merengkuh ilmu pengetahuan modern dan teknologi yang dihasilkannya. ${ }^{7}$ Pandangan manusia mengubah keyakinan akan kodrat

\footnotetext{
*Penulis adalah dosen pada Institut Agama Islam Negeri Palangka Raya, ia memperoleh gelar Magister Humaniora (M.Hum) di UGM Yogyakarta pada tahun 2003, Program Studi Ilmu Filsafat. Alamat Kantor: Sekolah Tinggi Agama Islam Negeri Palangka Raya Jl. G. Obos Komp. Islamic Centre Palangka Raya Kalimantan Tengah 73112

${ }^{1}$ Kai Nielsen, 1971, Reason and Practice a Modern Introduction to Philosophy (New York: Harper and Row Publishers, 1971), hlm. 9.

${ }^{2}$ Seyyed Hossein Nasr, The Garden of Truth (New York, Harper One, 2008), hlm. 4. hlm. 9 .

${ }^{3}$ P. Leenhouwers, P., 1988, Manusia dalam Lingkungannya, terj. K.J. Veeger (Jakarta: Gramedia, 1988),

${ }^{4}$ Hardono Hadi, Epistemologi (Yogyakarta: Kanisius, 1999), hlm. 29-30

${ }^{5}$ Peter Carruthers, Human Knowledge and Human Nature (New York: Oxford University Press, 1995), hlm. 2.

${ }^{6}$ Bambang Sugiharto, Posmodernisme (Yogyakarta: Kanisius, 2001), hlm. 21.

${ }^{7}$ Seyyed Hossein Nasr, Man and Nature The Spiritual Crisis of Modern Man (Chicago: ABC International Group Inc, 1997), hlm. 17.
} 
kebebasan dan kemampuan diri. Agama sebagai tempat kodrat penciptaan dan ajaran keselamatan dianggap tidak relevan.

One of the reasons why religion seems irrelevant today is that many of us no longer have the sense that we are surrounded by the unseen. Our scientific culture educates us to focus our attention on the physical and material world in front of us. ${ }^{8}$

Keterpurukan ini, terutama di Barat, menurut Bertrand Russel, sebagaimana dibenarkan oleh Oliver L. Reiser, berangkat dari tiga faktor, yakni: Bibel, filsafat Yunani, dan revolusi industri. ${ }^{9}$ Bibel mempengaruhi kehidupan tradisional keagamaan, filsafat Yunani membawa jalan menuju ilmu pengetahuan dan politik, dan revolusi industri memberikan persoalan yang dihasilkan oleh mesin peradaban. Ketiga faktor ini meski berkesinambungan, tetapi tidak harmonis. Komponen Filsafat Yunani yang rasional tidak bisa berdamai dengan kekristinan, sedangkan etika kekristinan dengan bisnis dan industri tidak selalu sejalan.

Jika menurut Verhaak dan Haryono, ${ }^{10}$ dalam kurun terakhir muncul tokoh filsafat ilmu pengetahuan baru, seperti: Thomas Kuhn, Imre Lakatos, dan Paul Feyerabend, maka menurut Huston Smith, pada dekade ini muncul Seyyed Hossein Nasr (berikutnya Nasr) sebagai pemikir fenomenal di berbagai bidang.

Nasr membandingkan istilah yang dimunculkan berdasarkan tradisi Barat dan Islam. Nasr menengahkan istilah "filsafat" dan "hikmah" dalam kedua tradisi tersebut. " Istilah hikmah dinukil berdasarkan ayat Al-Qur'ãn, ayat tersebut berbunyi:

Allah memberikan hikmah kepada siapa yang Dia kehendaki. Barangsiapa diberi hikmah, sesungguhnya dia telah diberi kebaikan yang banyak. Dan tidak ada yang dapat mengambil pelajaran kecuali orang-orang yang mempunyai akal sehat. (Q.S. AlBaqarah [2]:269). ${ }^{12}$

Menurut Kuntowijoyo, manusia dapat memiliki hikmah ketika ia sanggup membentuk perilaku sejalan dengan Al-Qur'ãn, dalam level moral, sosial, dan sistem Islam, tidak terkecuali Ilmu Pengetahuan, ini berarti mencakup wawasan epistemologis. ${ }^{13}$

Nasr menganggap metode ilmiah hanya salah satu upaya manusia mengungkapkan kebenaran itu karena orang dapat saja kembali kepada adat istidat, tradisi, atau agama. ${ }^{14}$

Islam menjaga semangat kebenaran tidak terpaku pada satu term saja. Islam tidak hanya membahas apa yang wajib dan haram bagi umat, tetapi juga membahas apa yang perlu diketahui. ${ }^{15}$ Nasr mengemukan hal demikian karena dalam Islam terdapat hubungan dua arah antara vertikal dan horizontal, subjek dan objek.

\footnotetext{
${ }^{8}$ Karen Armstrong, A History of God: the 4000-year Quests of Judaism Christianity and Islam (New York: Alfred A. Knopf, 1993), hlm. 4.

${ }^{9}$ Oliver L. Reiser, Cosmic Humanism (Massachusetts: Schenkman Publishing CO, 1966), hlm. xvi.

${ }^{10}$ C. Verhaak, dan R.Haryono Imam, Filsafat Ilmu Pengetahuan (Jakarta: Gramedia, 1989), hlm. 163.

${ }^{11}$ Seyyed Hossein Nasr, Islamic Philosophy ..., hlm. 35.

${ }^{12}$ Kementerian Agama RI, Al-Qur'andan Terjemahnya (Jakarta: PT Sinergi Pustaka Indonesia, 2012), hlm. 56-57.

${ }^{13}$ Kuntowijoyo, Islam sebagai Ilmu (Yogyakarta: Tiara Wacana, 2006), hlm. 11. hlm. 86 .

${ }^{14}$ Seyyed Hossein Nasr, Knowledge and Sacred (New York: State University of New York Press, 2011),

${ }^{15}$ Osman Bakar, Tauhid dan Sains, terj. Yuliani Liputo (Bandung: PustakaHidayah, 1994), hlm. 11. 
The nature of this inner reality, which humans bear in their essence, is elucidated by traditional Islamic philosophy, which is wedded at once to the intellect and revelation and brings out the relation between human-kind and God, the cosmos and human society. ${ }^{16}$

Cara sederhana mengetahui manfaat dan kelemahan ilmu pengetahuan dengan menelususri sejarah filsafat dan ilmu. Hal ini selalu berkaitan dengan Barat, terutama dari sudut sejarah filsafat, semenjak zaman Yunani Kuno hingga dewasa ini yang hanya memiliki plot narasi yang kurang lebih jelas, pertarungan antara mitos dan logos.

Meminjam istilah Budi F. Hardiman, ${ }^{17}$ mitos dianggap sebagai antagonis yang dimatikan oleh kemenangan logos sebagai protagonis. Dalam perjalanan sejarah perkembangan filsafat, metode filsafat secara radikal berubah akibat renungan Bapak filsafat Modern Descartes yang di kemudian hari memunculkan filsafat modern dengan berbagai aliran. $^{18}$

Dewasa ini logos diwakili oleh kehadiran dunia sains yang kemudian menjadi saintisme. Saintisme identik dengan modernisme. Modernisme menjadi mitos baru karena dianggap mampu menyelesaikan semua persoalan hidup. Jika mitos ditolak, dihancurkan oleh logos, dan logos berubah menjadi mitos baru, maka kelak muncul yang "baru" lagi. ${ }^{19}$

Gerakan penolakan itu hampir terdapat pada setiap abad. Thales yang dianggap sebagai filsuf pertama dan para penerusnya (Anaximenes dan Anaximandros) meruntuhkan pandangan masyarakat Yunani dengan menerangkan peristiwa alam tanpa harus merujuk pada dewa-dewi Yunani, sementara pada Abad Pertengahan para filsuf Islam memproklamirkan diri modern dalam menentang para pemikir pra-Islam ${ }^{20}$.

Akan tetapi, modernisme sebagai logos yang dianggap mewakili rasionalisme ternyata tidak dapat menyelesaikan semua persoalan manusia. Contoh, kasus pembunuhan dan bunuh diri pada masyarakat perkotaan sebagai representasi peradaban modern karena kegagalan manusia dalam menghadapi kehidupan. Manusia terbawa pada apa yang disebut oleh Bertens dengan filsafat tanpa etika. ${ }^{21}$

Modernisme yang pada awal perkembangannya ingin membebaskan manusia dari mitos sejak periode Yunani dan tirani yang dibentuk oleh institusi agama pada Abad Pertengahan, ternyata melakukan penghancuran terhadap nilai-nilai kemanusian. Penalaran yang dibangun sebagai kritik atas mitos itu berganti menjadi mitos baru, ilusi baru, tuhan baru dalam bentuk ilmu pengetahuan dan teknologi, manusia modern diperbudak oleh hasil kreatifitasnya sendiri. ${ }^{22}$ Agama menjadi terpinggirkan, mulai disingkirkan, dan lama-lama terlupakan.

\footnotetext{
${ }^{16}$ Seyyed Hossein Nasr, Islam in the Modern world (New York: Harper One, 2011), hlm. 148.

${ }^{17}$ Budi F. Hardiman, Ilmu-Ilmu Sosial dalam Diskursus Modernisme dan Pasca-Modernisme, Suplemen Ulumul Qurán, Nomor 1, Vol., V, Th. 1994, hlm. 1.

${ }^{18}$ Roger Scruton, Sejarah Singkat Filsafat Modern dari Descartes sampai Wittgenstein, terj.Zainal Arifin Tandjung (Jakarta: Pantja Simpati, 1986), hlm. 27.

${ }^{19}$ K. Bertens, Sejarah Filsafa tYunani (Yogyakarta: Kanisius, 2002), hlm. 21-22.

${ }^{20}$ Robert C. Solomon dan Kathleen M. Higgins, Sejarah Filsafat, terj, Saut Pasaribu (Yogyakarta: Yayasan Bentang Budaya, 2002), hlm. 348.

${ }^{21}$ Bertens, K., Panorama Filsafat Modern, (Jakarta: Gramedia, 1987), hlm. 41 dan 42.

${ }^{22}$ Maryam Jameelah, Islam dan Modenisme, terj. A. Jainuri dan Syafiq A. Mughni (Surabaya: Usaha Nasional, tt), hlm. 40.
} 
Agama dikemukakan karena elegi manusia modern terperangkap dalam dunia yang kehabisan nilai sakralnya. Manusia kehilangan atau melupakan mata hati. ${ }^{23}$ Oleh karena itu diperlukan keseimbangan dalam diri manusia karena berada di antara Tuhan sebagai yang menciptakannya dan alam semesta sebagai barang ciptaan. ${ }^{24}$ Nasr mengistilahkan keberadaan manusia itu berada di antara langit dan bumi. ${ }^{25}$ Agar seimbang, manusia melakukannya dengan pencapaian ilmu pengetahuan dan kasih sayang yang bermuara pada satu sumber, yakni Tuhan. Hal itu terwujud dalam perbuatan manusia karena di dalam diri manusia terdapat kebaikan. ${ }^{26}$

Nasr memandang, untuk memahami ilmu pengetahuan Islam dan hakikatnya, dibutuhkan pemahaman tentang prinsip Islam, meskipun gagasan ini sulit diungkapkan dalam term modern dan terkesan aneh bagi yang terbiasa dengan cara pola pikir lain di luar Islam. ${ }^{27}$ Bagi Nasr, jika ada kebenaran dalam ilmu pengetahuan modern, itu hanya bagian kecil dari filsafat dan penalaran Islam. $^{28}$ Pandangan yang dimunculkan Nasr dan tawaran epistemologinya relevan dengan kenyataan sekarang.

Rumusan dalam penelitian ini adalah: 1) Pandangan Seyyed Hossein Nasr terhadap modernisme ilmu pengetahuan?; 2) Bagaimana yang dimaksud dengan meta-epistemologi yang ditawarkan Seyyed Hossein Nasr dalam memandang metode yang ada?

Sesuai dengan rumusan masalah, penelitian ini bertujuan: 1) Mengetahui apa yang dimaksud dengan modernisme ilmu pengetahuan?; 2) Mendalami epistemologi Seyyed Hossein Nasr. Adapun manfaat penelitian ini diharapkan dapat: 1) Menyumbangkan pemikiran bagi kemajuan epistemologi sebagai cabang filsafat; 2) Menambah khazanah intelektual dalam bidang kefilsafatan dan keislaman.

\section{KAJIAN TEORITIK}

Banyak orang menganggap dunia Barat merupakan sentral ilmu pengetahuan, kendati dalam sejarah ilmu pengetahuan terbukti ada sumbangsih dari belahan lain seperti Mesir, Cina, dan India. Tidak boleh dilupakan kehadiran para filsuf Islam seperti: Al-Kindi, AlFarabi, Ibnu Sina, Imam Al-Ghazali, dan Ibnu Rusyd yang menyebarkan filsafat Aristoteles ke Benua Eropa melalui Spanyol dan mewariskannya kepada kaum Patristik dan Skolastik pada masa Abad Kegelapan. ${ }^{29}$

Pada zaman Yunani Kuno, ilmu pengetahuan tidak dibedakan dengan filsafat karena keduanya didapat dari rasio manusia. Pada zaman modern muncul kebutuhan untuk memisahkan secara jelas kelompok ilmu pengetahuan modern dari filsafat karena terdapat perbedaan menyolok: filsafat bercorak spekulatif, sedangkan ilmu pengetahuan modern

\footnotetext{
${ }^{23}$ Seyyed Hossein Nasr, Man and Nature ..., hlm. 20.

${ }^{24}$ Ibid., hlm. 136.

${ }^{25}$ Seyyed Hossein Nasr, Knowledge and Sacred ..., hlm.160.

${ }^{26}$ Seyyed Hossein Nasr, The Garden of Truth (New York: Harper One, 2008), hlm. 82.

${ }^{27}$ Seyyed Hossein Nasr, Science and Civilization in Islam (Cambridge: The Islamic Text Society, 2007), hlm. 22 .

${ }^{28}$ Oliver Leaman, Pengantar Filsafat Islam Sebuah Pendekatan Tematis, terj. Musa Kazhim dan Arif Mulyadi (Bandung: Mizan, 2001), hlm. 62.

${ }^{29}$ KoentoWibisono, "Ilmu Pengetahuan Sebuah sketsa Umum Mengenai Kelahiran dan Perkembangan sebagai Pengantar untuk Memahami Filsafat Ilmu" dalam Tim Dosen Filsafat Ilmu Fakultas Filsafat UGM, Filsafat Ilmu Sebagai Dasar Pengembangan Ilmu Pengetahuan (Klaten: Intan Pariwara, 1997), hlm. 2.
} 
menerapkan metode empiris, eksprimental, dan induktif. Semua cabang ilmu pengetahuan dinyatakan sebagai ilmu empiris. ${ }^{30}$

Gambaran yang dibangun berdasarkan pengetahuan dan hidup semacam ini memunculkan pandangan baru dan dapat menggoncang pandangan lama, termasuk kosmologi dan metafisika yang menurut J. Sudarminta bersumber pada agama-agama, ${ }^{31}$ oleh Nasr disebut tradisi. ${ }^{32}$

Klaim ilmu positif yang dikembangkan Barat sebagai satu-satunya yang berhak mengatasnamakan kebenaran perlu dipertanyakan. Bahkan, ada klaim bahwa ilmu pengetahuan modern identik dengan ilmu pengetahuan. ${ }^{33}$ Ilmu pengetahuan yang demikian itu akan mengancam demokrasi, tradisi, dan kebenaran relatif yang dimiliki orang.

Sebagai landasan teori dalam penelitian ini dipergunakan aspek metodologis, kelahiran, sejarah, dan perkembangan ilmu pengetahuan, mengingat pandangan Nasr yang beranggapan ilmu pengetahuan itu tidak diam; diam dalam pengertian karena ilmu pengetahuan mempunyai metode baku yang dianut ilmuwan sehingga menjadi kaku.

Ilmu pengetahuan modern tidak dapat memecahkan semua persoalan hidup. Poole Ross melukiskan dengan prihatin, masyarakat Barat modern telah menyusun konsep ilmu pengetahuan yang mendepak kemungkinan pengetahuan berkenaan dengan moral; moralitas tidak menjadi soal keyakinan rasional, tetapi soal opini subjektif. Di Dunia yang menolak iman, moralitas dapat mempertahanankan otoritas yang diperlukan untuk memerankannya di dalam kehidupan sosial dan individual. ${ }^{34}$

Fakta, sejarah peradaban dihiasi darah sejak kehadiran manusia. Sejarah perang tidak dapat melepaskan tinta penanya atas nama Tuhan, Perang Salib yang terjadi sepanjang abad ke-11 sampai ke-15, menyisakan traumatik mendalam bagi ribuan orang Yahudi, Nasrani, dan Islam, hanya contoh cerita besar ketidakberdayaan manusia memahami tuhan yang diklaim sebagai realita tertinggi untuk menghentikan pertengkaran antar manusia. ${ }^{35}$ Perbedaan esensial masing-masing agama terletak pada "imajinasi" penggambaran Tuhan. Aspek ketuhanan menjadi pluralitas manifestasi kepercayaan ilahiah. ${ }^{36}$

Persetujuan universal dimunculkan karena terdapat prinsip tunggal dari segala sesuatu yang satu dan selalu sama dengan pengetahuan manusia. Pengetahuan manusia misalnya, ia sempurna diturunkan secara langsung dari Tuhan, lalu terpecah-pecah, akan tetapi ia dapat bertahan dengan tradisi. Kebenaran sejati adalah apa saja yang datang dari Tuhan.

Kebenaran itu dari Tuhanmu, maka janganlah sekali-kali engkau (Muhammad) termasuk orang-orang yang ragu (Q.S. Al-Baqarah [2]:147). ${ }^{37}$

\footnotetext{
${ }^{30}$ The Liang Gie, Pengantar Filsafat Ilmu (Yogyakarta: Liberti, 2000), hlm. 11-15.

${ }^{31}$ J. Sudarminta, "Sains dan Masalah Ketuhanan", dalam Diskursus, Vol. 1, No. 1. (Jakarta: Sekolah Tinggi Filsafat Driyarkara, 2002), hlm. 35-36.

${ }^{32}$ Seyyed Hossein Nasr, Science and Civiization ..., hlm. 337. hlm. 173.

33 James F. Harris, Against Relativism: A Philosophical Defense Method (Chicago: Open Court, 1992),

${ }^{34}$ Ross, Poole, Moralitas dan Modernitas, terj. F. Budi Hardiman (Yogyakarta: Kanisius, 1993), hlm. xix$\mathrm{xxx}$.

${ }^{35}$ Karen Armstrong, PerangSuci, terj. Hikmat Darmawan (Jakarta: PT. IkrarMandiriabadi, 2011), hlm. 701.

${ }^{36}$ Seyyed Hossein Nasr, The Heart of Islam (New York: Harper One, 2004), hlm. 316.

${ }^{37}$ Kementerian Agama RI, Al-Quran ...., hlm. 28.
} 
Epistemologi menjadi berarti karena masyarakat modern jauh dari nilai-nilai ilahiah sebagai penyebab kegersangan kehidupan yang membuat manusia tidak lagi harmoni dengan alam.

\section{SEYYED HOSSEIN NASR DALAM KHAZANAH PEMIKIRAN ISLAM MODERN}

Seyyed Hossein Nasr dilahirkan pada Tahun 1933 di Tehran, Republik Islam Iran. Ayahnya bernama Seyyed Valiallah, kelahiran $1871 .{ }^{38}$ Nasr mengenal filsafat dan teologi sejak dini karena ayahnya sangat peduli terhadap pendidikan yang memadukan gaya tradisional dan modern, bahkan sejak umur sepuluhan ia sudah mulai berkenalan dengan filsafat Barat.

Nasr dikirim oleh orang tuanya ke Amerika Serikat, tepatnya ke New York, pada tahun 1945 dan ia mulai mempelajari Bahasa Inggris dengan seksama. ${ }^{39}$ Setelah empat tahunan di kota metropolitan ini, ia berpindah ke Buston. Di sini Nasr mulai berkenalan dengan Bertrand Russel, yang secara meyakinkan berpendapat bahwa kemungkinan itu tidak ada di dunia nyata ini. Hal ini membuat Nasr semakin tertarik dengan dunia ilmiah sebagaimana ia juga menyukai hal-hal yang berkaitan dengan kesusasteraan. ${ }^{40}$

Pada tahun 1958, Nasr kembali ke Iran dan mempelajari Islam tradisional. Sekembalinya ke barat, Nasr mengambil posisi di University of Edinburgh, Temple University, dan sejak tahun 1984 ia memberi kuliah di The George Washington University di mana ia sekarang menjadi Profesor pada studi Islam dan tradisional. Nasr membantu dengan perencanaan dan perluasan program akademik studi Islam dan Iran di beberapa perguruan tinggi seperti Princeton, University of Utah, dan University of Southern California, Amerika Serikat.

Nasr dikenal sebagai filsuf Islam dan sarjana perbandingan agama, juga disebut-sebut sebagai pengikut Frithjof Schoun. Huston Smith, ahli perbandingan agama, tidak tanggungtanggung, menempatkankan Nasr sejajar dengan Sokrates dan Plato. ${ }^{41}$ Dengan demikian, banyak tempat tersedia untuk Nasr mengingat ketokohannya yang menonjol, terutama yang berkaitan dengan pemahaman Islam tradisional dan kontemporer. Wajar jika Nasr acap kali diundang sebagai nara sumber pada forum ilmiah internasional di negara-negara Eropa, Amerika, Timur Tengah, dan Asia.

\section{MODERNISME DAN KLAIM KEBENARAN}

Menurut Kamus Besar Bahasa Indonesia, modernisme berarti: Gerakan yang bertujuan menafsirkan kembali doktrin tradisional, menyesuaikannya dengan aliran-aliran modern dalam filsafat, sejarah, dan ilmu pengetahuan. ${ }^{42}$

Kebanyakan orang merujuk pada kata latin modernus yang kali pertama digunakan di dunia Nasrani tahun 400-an yang menunjukkan perpindahan dari masa Romawi menuju masa Masehi, sedangkan yang banyak disepakati bahwa modernisme mulai berjalan di Eropa sejak

\footnotetext{
${ }^{38}$ William C. Chittick, The Essential Seyyed Hossein Nasr, (Bloomington: World Wisdom, 2007), hlm. ix.

${ }^{39}$ Ibid., hlm. X.

${ }^{40}$ Ibid.

${ }^{41}$ Huston Smith, Foreword dalam The Essential Seyyed Hossein Nasr, ed.William C. Chittick (Indiana: World Wisdom, 2007), hlm. vii.

${ }^{42} \mathrm{http}: / /$ kamusbahasaindonesia.org/modernisme (online 12 Agustus 2016) 
abad ke-16. ${ }^{43}$ Modernisme tidak dapat dipisahkan dari sejarah Eropa yang berlangsung ribuan tahun, dimulai dari masyarakat Yunani Kuno yang memisahkan lembaga kebudayaan, seni dan berbagai cabang pengetahuan lainnya dari agama. ${ }^{44}$

Para filsuf awal seperti Thales, Anaximandros, dan Anaximenes mempersiapkan bahan mentah yang banyak dalam penekanan betapa penting teori mengenai kosmos dan status matematika sebagai pengetahuan ideal. ${ }^{45}$ Akhirnya, modernisme adalah semacam pemberontakan radikal dalam rangka melawan agama dan nilai-nilai spiritual yang terkandung di dalammnya. Mazhab ini tidak hanya tumbuh dan berkembang di tanah kelahirannya, Eropa, tetapi menjalar ke seluruh penjuru dunia, menjadi kepercayaaan universal. Bangsa yang "memeluk" mazhab ini dianggap sebagai bangsa maju dan beradab, sedangkan yang menetang dianggap sebagai bangsa terkebelakang dan tidak beradab.

Gejala semacam ini menyebabkan terjadinya distorsi pada nilai kemanusiaan. Agama dan Tuhan diabaikan, iman menguap. Ada kecenderungan manusia modern memerankan dirinya sebagai "tuhan" di atas bumi dan membuang dimensi transendental dari kehidupannya.

Modernisme dianggap sebagai zaman keemasan rasionalistik dan pendewaan terhadap akal pikiran manusia. Akal dan pengalaman dipakai sebagai sumbu pengetahuan yang secara alami terdapat pada manusia, meskipun terdapat kecenderungan memilih satu di antara keduanya. Kecenderungan tersebut memunculkan dua aliran yang bertentangan: rasionalisme dan empirisme.

Rasionalisme berpendapat akal atau rasio adalah sumber pengetahuan paling memadai dan dapat dipercaya memenuhi syarat umum dan mutlak yang dituntut oleh pengetahuan ilmiah. Akal tidak membutuhkan pengalaman karena pengalaman hanya dapat dipakai untuk menguatkan pengetahuan yang didapat melalui akal. Emperisme berpendapat pengalaman atau empiri, baik batiniah maupun lahiriah adalah sumber pengetahuan. Akal bukan sumber pengetahuan karena hanya mengolah bahan-bahan yang diperoleh pengalaman. ${ }^{46}$

Dengan demikian, muncul klaim bahwa intelektualisme, diwakili modernisme, terutama Barat adalah "pisau" analisis tertajam untuk membedah persoalan umat manusia. Klaim ilmu positif yang dikembangkan Barat sebagai satu-satunya yang berhak mengatasnamakan kebenaran perlu dipertanyakan. Bahkan, ada klaim bahwa ilmu pengetahuan modern identik dengan ilmu pengetahuan. ${ }^{47}$ Ilmu pengetahuan yang demikian itu akan mengancam demokrasi, tradisi, dan kebenaran relatif yang dimiliki orang.

Materialisme menghancurkan tatanan dan nilai sendi-sendi kehidupan. Akibatnya, masyarakat panik, pegangan hidup mulai goyah dan jalan hidup pun mulai kehilangan arah. Padahal, tujuan fisafat pada awalnya, juga ilmu pengetahuan sekarang dan yang dihasilkannya adalah pengetahuan yang benar, jika tidak, maka gejala semacam ini menyebabkan terjadinya

${ }^{43}$ Putro, Suadi, Islam Menghadapi Tantangan Kemodernan Pandangan Muhammad Arkoun, dalam Tradisi Kemodernan dan Metamodernisme, Ed. Johan Hendrik Meuleman, (Yogyakarta: Lkis, 1996), hlm. 100.

${ }^{44}$ Maryam Jameelah, Islam dan Modernisme, terj. A. Jainuri dan Syafiq A. Mughni, (Surabaya: Usaha Nasional, tt.), hlm. 23

${ }^{45}$ Syairil Fadli, Kritik Feyerabend atas Determinisme Ilmu Pengetahuan, Tesis, (Yogyakarta: UGM, 2002), hlm. 59.

${ }^{46}$ Harun Hadiwijono, Sari SejarahFilsafat 2, (Yogyakarta: Kanisius, 1990), hlm. 18.

47 James F. Harris, Against Relativism: A Philosophical Defense Method (Chicago: Open Court, 1992), hlm. 173. 
distorsi pada nilai-nilai kemanusiaan. Oleh karena itu, kekacauan ini harus dipulihkan, sebagaimana yang digambarkan dan diupayakan oleh Nasr berikut.

\section{KONSEPSI SEYYED HOSSEIN NASR TENTANG KEBENARAN}

Manusia pada awalnya menganggap dirinya sebagai viator mundi, makhluk yang melancong ke muka bumi. Manusia memandang bumi seakan-akan menyediakan segalanya, buah-buahan misalnya, namun, lambat laut apa yang tersedia itu mulai habis. Kini manusia menganggap dirinya sebagai faber mundi, makhluk yang menciptakan dunianya. ${ }^{48}$

Tantangan alam sudah teratasi berkat kemajuan ilmu pengetahuan dan teknologi; manusia tidak saja mampu mengontrol dunia fisis tetapi juga menentukan tujuan sejarahnya atas tanggung jawab sendiri dengan segala konsekuensinya. Manusia sanggup melenyapkan takdir dan nasib malang yang pernah menghambat kebebasannya. Manusia dipandang sebagai makhluk otonom, bebas, dan mandiri. Akan tetapi, untuk sampai pada kesadaran faber mundi, manusia memerlukan waktu lama, di antaranya memahami masa lampau guna menjaga hari ini agar berlanjut sampai masa akan datang.

Masyarakat modern didominasi oleh pandangan hidup materialistik, pragmatis dan sekularistik. Pandangan hidup semacam ini sangat menjunjung tinggi nilai material dan menafikan aspek spiritual. Terjadi desakralisasi kehidupan. Realitas hidup adalah "kini/kekinian". Masa depan, apalagi hidup sesudah mati, merupakan hal yang nisbi. Jika mereka beragama, tampaknya agama hanya dianggap sebagai identitas simbolik, bukan sebagai nilai yang tercermin dalam perilaku. Konsekuensinya terjadi pembusukan nilai agama akibat agama melekat pada individu yang mengartikulasikan nilainya sebatas simbol semata, misal untuk keperluan menikah.

Pandangan hidup seperti di atas berpadu dengan falsafah humanistik esktrem yang menjadikan manusia sebagai pusat dan ukuran segala-galanya. Di satu sisi mereka mengagungkan kedudukan manusia sebagai makhluk yang mulia, tetapi di sisi lain justeru menginjak-injak harkat dan martabat manusia. Di samping itu humanisme hipokrit juga melanda dunia modern. ${ }^{49}$

Masyarakat modern yang dibangun rasionalisme mulai menyadari kebosanan luar biasa. Modernisme yang semula menjanjikan pembebasan dan kemerdekaan dari tirani agama dan tradisi skolastik, malah melakukan penghancuran terhadap nilai-nilai kemanusian yang sejati. Rasionalitas modernitas yang awalnya sangat kritis terhadap mitos tradisional, berubah menajdi mitos dalam bentuk ilmu pengetahuan dan teknologi yang dihasilkannya. Meminjam istilah Agus Purwadi, seakan-akan manusia bisa hidup dengan makan roti saja, tanpa unsur lain, yakni sprtitualitas-religius. ${ }^{50}$

Kerumitan ini muncul berakar dari sejauh mana manusia meletakkan pengetahuan sebagai asas dalam melakukan perbuatan.

\footnotetext{
${ }^{48}$ Harry Hamersma, Tokoh-Tokoh Filsafat Barat Modern (Jakarta: Gramedia, 1986), hlm. 3.

49 Barsihannor, Agama dan Sains di Era Postmodernisme, Makalah, Disampaikan di depan Rapat Senat Terbuka Luar Biasa dalam rangka Wisuda Sarjana STAI Babussalam Kab. Kepulauan Sula Provinsi Maluku Utara, Sabtu 16 Mei 2015.

${ }^{50}$ Agus Purwadi, Teologi Filsafat dan Sains, (Malang: UMM Press, 2002), hlm. 70. 
Tidaklah engkau mengetahui bahwa siapa yang ada di langit dan siapa yang ada di buni bersujud kepada Allah, juga matahari, bulan, bintang, gunung-gunung, pohonpohon, hewan-hewan yang melata dan banyak di antara manusia? Tetapi banyak yang pantas mendapatkan azab. Barang siapa dihinakan Allah, tidak seorang pun yang akan memuliakannya. Sungguh Allah berbuat apa saja yang Dia Kehendaki (QS. Al-Hajj $[22: 18){ }^{51}$

Ayat di atas menggambarkan realitas seperti manusia dan alam semesta tunduk atas sujud pada nilai yang adi kodrati. Materi pun tidak bebas nilai karena mempunyai tujuan sebagaimana sang Penciptanya. Metafisika menjadi penting sebagai bentuk pengetahuan mulai menghilang dan ikut bertanggung jawab secara langsung terhadap keadaan zaman. Metafisika di mata Nasr adalah satu dan harus dinamai metafisika tunggal, adalah ilmu yang real, tentang asal-usul dan akhir segala hal, yang absolut, dan pancarannya relatif.

Nasr akhirnya menawarkan agar manusia kembali kepada dimensi pengetahuan tradisional dan berketuhanan. Kondisi contoh di atas terjadi akibat tidak ada keseimbangan antara dimensi zikir dan pikir, rasa dan rasio. Akal tidak diharmoniskan dengan wahyu, aspek individu tidak diimbangi dengan sosial, kreativitas tidak dibarengi dengan cita dan kasih sayang.

Kehadiran Islam melampaui kecenderungan bersifat temporal, karena ia bukan sistem penjelasan diri maupun pembenaran diri, ia terbuka. Misalnya saja tentang kesatuan dan keutuhan dunia melalui kasih sayang, konsep tentang tuhan, termasuk agama sebagai kemampuan alamiah manusia dalam mencapai kabahagian. Spritual dan intelektual dijadikan oleh manusia sebagai sarana duniawi untuk mengekspresikan diri sesuai dengan kapasitas dan kebutuhan diri pribadi maupun orang banyak. ${ }^{52}$

Barat tertarik mengkaji Islam ketika di dunia Islam juga muncul berbagai mazhab yang menyebabkan pertentangan antara Islam tradisional dan modern, meskipun keduanya sama-sama berakar pada Al-Qur'ãn dan Al-Hadits. ${ }^{53}$ Hal tersebut ditemui pada sebagian besar filsuf Islam yang juga "berprofesi" sebagai ilmuwan. Al-Kindi menulis matematika, fisika, metafisika, ensiklopedia, dan logika. Ibnu Sina adalah dokter yang filsuf, atau filsuf yang dokter. Tokoh ini sangat berpengaruh dalam bidang imu pengetahuan dan pengobatan. Ibnu Rushd (Latin Everroes) menulis tentang fisika, astronomi, pengobatan, hukum, dan metafisika. Figur ini begitu dihormati oleh para tokoh dunia Barat seperti Thomas Aquinas dan Dante, yang hidup pada masa Skolastik. ${ }^{54}$ Kemasyhuran para filsuf Islam begitu dominan pada masa Skolastik, sehingga berpengaruh besar ketika muncul masa Renaisans.

Meskipun demikian, Nasr mengingatkan, kehidupan manusia tidak hanya di muka bumi, tetapi juga di akhirat. Oleh karena itu, dalam diri manusia harus terdapat keseimbangan antara dunia dan akhirat. Manusia tidak hanya memanfaatkan akal untuk menganalisa segala sesuatunya, tetapi juga kekuatan mental terhadap berbagai alasan di luar akal yang terbatas. Membangun rumah Misalnya, lazim jika orang menggunakan jasa tukang kayu, akan tetapi

\footnotetext{
${ }^{51}$ Kementerian Agama RI, Al-Quran ....................., hlm. 465.

${ }^{52}$ Seyyed Hossein Nasr, Tentang Tradisi, dalam Perennialisme Melacak Jejak Filsafat Abadi, ed., Ahmad Norma Permata (Yogyakarta: Tiara Wacana, 1996), hlm. 155.

${ }^{53}$ Seyyed Hossein Nasr, Islam in the Modern World: Challenged by the West, Threatened by Fundamentalism, Keeping Faith by Tradition (New York: Harper One, 2012), hlm. 1-2.

${ }^{54}$ Nasr, Science and Civilization ......................... hlm. 49.
} 
yang akan menempati rumah itu dan tukang yang membangun rumah tersebut tidak tenang kalau tidak ada doa yang dipanjatkan.

Kedamaian dan impian yang dikehendaki modernisme tidak akan terwujud jika manusia tidak harmonis dengan alam. Untuk bisa harmonis dengan alam itu, manusia juga harus harmonis dengan agama, dan itu semua bersumber dari Maha Mencipta. Manusia yang mengaku beriman kepada sang Pencipta sudah seharusnya juga harmonis dengan apa yang diciptakan, termasuk alam dan sesama manusia yang ada di dalamnya. Jika tidak manusia hanya berputar-putar tanpa titik pusat.

Titik pusat itu secara hierarki tertinggi ada pada Tuhan. Meskipun untuk itu manusia harus berusaha semaksimal mungkin mencapainya. Nasr, mengutip hadits yang cukup dikenal, yakni, "Barang siapa mengenal dirinya, ia mengenal Tuhannya." 55

Seiring perkembangan zaman dan manusia semakin banyak, kebenaran itu mulai kabur, bahkan bagi sebagian orang dianggap mimpi. Satu-satunya wadah kebenaran dapat ditemukan dalam keadaan utuh terdapat pada agama dan filsafat. Kebenaran dapat dicapai baik melalui ekspresi historis, maupun melalui intuisi intelektual. ${ }^{56}$

Keberhasilan perjumpaan Islam dengan pemikiran modern hanya bisa terjadi ketika pemikiran modern sepenuhnya dapat dipahami baik dasar maupun konsekuensi dengan cara prinsip pemikiran Islam, dan seluruh tradisi intelektual Islam. Nasr mengajukan harus kembali kepada syariat, meskipun Nasr sadar, hal ini akan berhadapan dengan berbagai lingkaran yang ada pada modernisme, sebut saja sekularisme, evolusisme, rasionalisme, eksistensialisme, agnotisme, relativisme, nihilisme, dan humanisme. ${ }^{57}$

Oleh karena itu, syariah itu harus diikuti dengan hikmah di tengah-tengah upaya membagkitkan kebijaksanaan. Hikmah atau haqiqah, terletak pada jantung wahyu Islam dan yang telah diuraikan dalam tradisi intelektual Islam pada umumnya dan filsafat khususnya. ${ }^{58}$ Perpaduan ini dapat dilihat pada manusia universal atau al-insan al-kamil. Manusia universal ini meliputi kata dan tindakan eternal tuhan.

Manusia universal adalah realitas Muhammad yang juga diwujudkan oleh umatnya ketika mengejawantahkan ajaran Islam dalam mengelola bumi dan lingkungan. Akhir dari pengetahuan suci ini adalah tercapainya tujuan kebebasan dan keterikatan; instrumen seluruh keberadaan manusia dan makna pemenuhan akhir manusia dan alam semesta yang diciptakan. Kebijaksanaan akan tetap berlaku selama manusia masih bersaksi kepada Allah sebagai Tuhan Yang Maha Esa dan Yang Mencipta sesuai dengan fitrah manusia. ${ }^{59}$ Sudah menjadi keharusan bagi filsafat Islam untuk menyatukan, menurut Nasr, mengawinkan, ${ }^{60}$ antara rasionalitas dan iluminasi batin, antara intelektual dan pengalaman spiritual, antara pemikiran rasional dan kesucian.

\footnotetext{
${ }^{55}$ Seyyed Hossein Nasr, Islamic Philosophy ............, hlm. 266.

${ }^{56}$ Seyyed Hossein Nasr, Tentang Tradisi ......, hlm. 148-149.

${ }^{57}$ Seyyed Hossein Nasr, Islamic Philosophy ............. hlm. 271.

${ }^{58}$ Ibid., hlm 272.

${ }^{59}$ Seyyed Hossein Nasr, Knowledge ...................... hlm. 328

${ }^{60} \mathrm{Nasr}$, Intelektual .........................., hlm. 87.
} 


\section{KESIMPULAN}

Berdasarkan paparan di atas, dapat ditarik kesimpulan sabagai berikut: 1) Seyyed Hossein Nasr, melihat modernisme yang pada awal perkembangannya berniat membebaskan manusia dari mitos sejak periode Yunani dan tirani yang dibentuk okeh institusi agama pada Abad Kegelapan, malah melakukan destorsi terhadap nilai-nilai kemanusian. Manusia modern diperbudak oleh hasil kreatifitasnya sendiri. Mazhab ini tidak menepati janji, ide dan nilai yang diwakilinya mengalami krisis. Akibatnya, tindakan rasional hanya memperhitungkan sarana paling efektif untuk mencapai tujuan; 2) Seyyed Hossein Nasr menawarkan agar siapapun kembali kepada agama, dalam hal ini Islam, sebagai pijakan, sehingga muncul kesatuan ontologi, epistemologi, dan aksiologi. Siapa pun perlu meningkatkan kesadaran tanggung jawab sosial, inteletual, dan spritual.

\section{DAFTAR PUSTAKA}

\section{BUKU}

Armstrong, Karen, A History of God: the 4000-year Quests of Judaism Christianity and Islam, New York: Alfred A. Knopf, 1993.

Armstrong, Karen, Perang Suci, terj., Hikmat Darmawan, Jakarta: PT. Ikrar Mandiriabadi, 2011.

Bakar, Osman Tauhid dan Sains: Esei-Esei tentang Sejarah dan Filsafat Sains, terj. Yuliani Liputo, Bandung: PustakaHidayah, 1994.

Bakker, Anton, Metode-Metode Filsafat, Jakarta: Ghalia Indonesia, 1986.

Bertens, K., Panorama Filsafat Modern, Jakarta: Gramedia, 1997.

, Sejarah Filsafat Yunani, Yogyakarta: Kanisius, 2002.

, Filsafat Barat Kontemporer Inggris - Jerman, Jakarta: Gramedia pustaka Utama, 2002.

Carruthers, Peter, Human Knowledge and Human Nature, New York: Oxford University Press, 1995.

Gie, The Liang, Pengantar Filsafat Ilmu, Yogyakarta: Liberti, 2000.

Hadiwijono, Harun, Sari Sejarah Filsafat Barat 2, Yogyakarta: Kanisius, 1980.

Hamersma, Harry, Tokoh-Tokoh Filsafat Barat Modern, Jakarta: Gramedia,1986.

Hardiman, F. Budi, Ilmu-Ilmu Sosial dalam Diskursus Modernisme dan Pasca-Modernisme, Suplemen Ulumul Qur'an, Nomor 1, Vol. V, Th. 1994.

Hadi, Hardono, Epistemologi,Yogyakarta: Kanisius, 1999.

Hadiwijono, Harun, Sari Filsafat Barat 2, Yogyakarta: Kanisius, 1980.

Harris, James F., Against Relativism: A Philosophical Defense of Method, Chicago: Open Court, 1992.

Jameelah, Maryam, Islam dan Modernisme, terj. A. Jainuri dan Syafiq A. Mughni, Surabaya: Usaha Nasional, $\mathrm{tt}$.

Kementerian Agama RI, Al-Qur'an dan Terjemahnya. Jakarta: SinergiPustaka Indonesia, 2012.

Kuntowijoyo, Islam sebagai Ilmu, Yogyakarta: Tiara Wacana, 2006.

Nasr, Seyyed Hossein, Intelektual Islam Teologi, Filsafat dan Gnosis, terj, Suharsono dan Jamaluddin MZ, Yogyakarta: CIIS Press, 1995. 
Nasr, Seyyed Hossein, Man and Nature: the Spiritual Crisis in the Modern Man, Chicago: ABC International Group Inc, 1997.

Nasr, Seyyed Hossein, Islam Religion History and Civilization, New York: Harper One, 2003.

Nasr, Seyyed Hossein, The Heart of Islam: Enduring Values for Humanity, New York: Harper One, 2004.

Nasr, Seyyed Hossein, Islamic Philosophy from Its Origin to the Present: Philosophy In The Land of Prophecy, New York: Suny Press, 2006.

Nasr, Seyyed Hossein, Science and Civilization in Islam, Cambridge: The Islamic Texts Society, 2007.

Nasr, Seyyed Hossein, The Garden of Truth: The Vision and Promise of Sufism, Islam Mystical's Tradition, New York: Harper One, 2008.

Nasr, Seyyed Hossein, Knowledge and the Sacred, New York: State University of New York Press, 2011.

Nasr, Seyyed Hossein, Tiga Mazhab Utama Fisafat Islam, terj., Ach Maimun Syamsuddin, Yogyakarta: IRCiSoD, 2014.

Nasr, Seyyed Hossein, Islam in the Modern World, New York: Harper One, 2012.

Leaman, Oliver, Pengantar Filsafat Islam Sebuah Pendekatan Tematis, terj. Musa Kazhimdan Arif Mulyadi, Bandung: Mizan, 2001.

Leenhouwers, P.,Manusia dalam Lingkungannya, terj. K.J. Veeger, Jakarta: Gramedia,1988.

Nasr, Seyyed Hossein, Tentang Tradisi, dalam Perennialisme MelacakJejak Filsafat Abadi, ed. Ahmad Norma Permata, Yogyakarta: Tiara Wacana, 1996.

Newton-Smith, W.H.,The Rationality of Science, London: Routledge and Kegan Paul,1981.

Nielsen, Kai, Reason and Practice a Modern Introduction to Philosophy, New York: Harper and Row Publishers, 1971.

Permata, Ahmad Norma, Perrenialisme: Melacak Jejak Filsafat Abadi, Yogyakarta: Tiara Wacana, 1996.

Poole, Ross, Moralitas dan Modernitas, terj.F. Budi Hardiman, Yogyakarta: Kanisius,1993.

Putro, Suadi, Islam Menghadapi Tantangan Kemodernan Pandangan MuhammaArkoun, dalam Tradisi Kemodernan dan Metamodernisme, ed. Johan Hendrik Meuleman, Yogyakarta: Lkis. 1996.

Purwadi, Agus, Teologi Filsafat dan Sains, Malang: UMM Press, 2002.

Reiser, Oliver L., Cosmic Humanism, Massachusetts: Schenkman Publishing CO, 1966.

Scruton, Roger, Sejarah Singkat Filsafat Modern dari Descartes sampai Wittgenstein, terj. Zainal Arifin Tandjung, Jakarta: Pantja Simpati, 1986.

Smith, Huston, Foreword dalam The Essential Seyyed Hossein Nasr, ed.William C. Chittick, Indiana: World Wisdom, 2007.

Solomon, Robert C., Higgins, Kathleen M., Sejarah Filsafat, terj. Saut Pasaribu, Yogyakarta: Yayasan Bentang Budaya, 2002.

Sugiharto, Bambang, Posmodernisme, Yogyakarta: Kanisius, 2001.

Verhaak, C., dan Imam, R. Haryono, Filsafat Ilmu Pengetahuan, Jakarta: Gramedia, 1989. 


\section{JURNAL}

Sudarminta, J., "Sains dan Masalah Ketuhanan”, dalam Diskursus, Vol. 1, No. 1. Hlm. 35-46. Jakarta: Sekolah Tinggi Filsafat Driyarkara, 2002.

Wibisono, Koento, "Ilmu Pengetahuan Sebuah sketsa Umum Mengenai Kelahiran dan Perkembangan sebagai Pengantar untuk Memahami Filsafat Ilmu" dalam Tim Dosen Filsafat Ilmu Fakultas Filsafat UGM, Filsafat Ilmu Sebagai Dasar Pengembangan Ilmu Pengetahuan, hlm. 1-10, Klaten: Intan Pariwara, 1997. 